\title{
Developing Information Literacy in the Malaysian Smart Schools: Resource-Based Learning as a Tool to Prepare Today's Students for Tomorrow's Society
}

\author{
Chan Foong Mae \\ Smart School Pilot Project Team \\ Educational Technology Division \\ Ministry of Education \\ 50604 Kuala Lumpur \\ Malaysia \\ foongmae@moe.edu.my
}

\begin{abstract}
Today's students are surrounded by more information coming from more sources than ever before. In order to deal with the vast amount of information they will encounter in school, life, and work, they must develop skills not required of previous generations. Since schools cannot teach all that students need to know, a better way is to teach them to manage the information resources. Although schools should still identify the basic information that students need to know, schools must also teach "information literacy", that is, the ability to find, interpret, use, and communicate information from a variety of sources. Resource-based learning is a tool to help students handle information. It is based on the belief that students learn best by interacting directly with learning resources instead of just listening to classroom lectures. The learning is in line with the Malaysian Smart School Concept in that it is more self-directed, self-paced, and self-accessed, and hopefully, more meaningful. Since the skills of information literacy cannot be taught in a content vacuum, resource-based learning integrates the classroom and the school resource centre or the school library. Students go through a problemsolving process that requires them to define the need for information, determine a search strategy, locate the needed resources, assess and understand the information they find, interpret the information, communicate the information, and finally, evaluate their conclusions in view of the original problem.
\end{abstract}

\section{Introduction}

This paper discusses a much required convergence of two concepts, one that has been around for a while ("information literacy") and one that is relatively new (the "Malaysian Smart School"). The concept of information literacy is not new; in fact, there is a relatively large body of literature, particularly of American, Canadian, Australian and South African origin. Historically, literacy was interpreted as a basic ability to read, write, and comprehend. Kuhlthau (1995) affirmed that to be literate was not only to recognise when information was required, but involved the ability to construct one's own knowledge through a process that gave meaning and self-interest to the notion of learning throughout a lifetime. However, more often than not, classroom teachers see information literacy as an add-on and not a genuine part of the business of education (Langford, 1998). 
The Malaysian Smart School concept was formally introduced to the world in 1997 (Ministry of Education, 1997). The Malaysian Smart School was set up to be the catalyst for a massive transformation in the Malaysian educational system, in line with and in support of the nation's drive to fulfil Vision 2020. This Vision calls for sustained, productivity-driven growth, which will be achievable only with a technologically literate, critically thinking work force prepared to participate fully in the global economy of the twenty-first century. Technology-supported Smart Schools will improve how the educational system achieves the National Philosophy of Education, while fostering the development of a work force prepared to meet the challenges of the next century.

Malaysia is planning to roll out the Malaysian Smart School concept to all the schools in the country in the year 2003. A three-year pilot project, which started in July 1999, involving less than one percent of the schools in the country, is due to end in December 2002. It is critical that school librarians, teacher librarians, or media coordinators, as important stakeholders in the Malaysian School System, help promote the Smart School as a vehicle for the realisation of the goals of information literacy in schools.

Teacher librarians know about information literacy from their perspective, but there seems to be a serious gap between what they know and what is being practised by classroom teachers in the implementation of pedagogy that includes information literacy as common practice. Information literacy is an important concept in the Smart School Conceptual Blueprint, but the term is not formally presented anywhere in the document.

At present, information literacy seems to be the responsibility of librarians and teacher librarians or media coordinators (as named in the Conceptual Blueprint). They write papers, organise conferences, develop plans, explore and support theories, but all this intellectual activity is far removed from everyday classroom practices, and does not translate into effective and considered change in the classroom. The understandings and skills that form information literacy have yet to become embedded into the classroom practices of teachers, the outcomes of education in the Information and Communications Age, and the Malaysian educational system. Too often information is understood as something that is teacher librarian-oriented and not part of the general curriculum. The concept of information literacy has yet to become part of the natural discourse of the design of curriculum units or pedagogical issues.

It is time that teacher librarians in Malaysia examine the golden opportunity presented by the imminent roll out of the Malaysian Smart School to implement goals and objectives of information literacy in the school system. Obviously, there is a need to learn from successful existing and on-going projects around the world, and merge this learning with unique local requirements to create something that can be adapted and adopted by the local system. This conference will help fulfil part of this need, but teacher librarians in the country must see that the Malaysian Smart School concept is not a fashionable luxury. They must see that it is the only sure way for them to move forward and make an impact in the educational system.

\section{Guiding Principles of the Malaysian Smart School}

Malaysia's National Philosophy of Education calls for "developing the potential of individuals in a holistic and integrated manner, so as to produce individuals who are intellectually, spiritually, emotionally, and physically balanced and harmonious". This philosophy underpins every element of the Malaysian Smart School conceptual model. 
The Malaysian Smart School is a systemic reinvention of the Malaysian educational system, and entails changing the culture and practices of Malaysia's primary and secondary schools. The reinvention involves moving away from memory-based learning designed for the average student to an education that stimulates thinking, creativity, and caring in all students, caters to individual abilities and learning styles, and is based on more equitable access. Students will be required to exercise greater responsibility for their own education, while more active participation by parents and the wider community will be sought.

The most distinctive feature of the Smart School will be a teaching and learning environment derived from the alignment of the curriculum, pedagogy, assessment, and teaching-learning materials in a mutually reinforcing and coherent manner. Students will be encouraged to progress at their own pace, and according to their varying capabilities, interests and needs. The students will also be given greater responsibility for managing and directing their own learning. The focus will be on students' searching, generating, and using knowledge with an emphasis on problem-solving and creativity. In the Smart School, it is hoped that students will develop the critical skills and acquire the knowledge they need for effective lifelong learning and full functioning as citizens in a changing society.

Clearly, the Conceptual Blueprint discusses the use of "information literacy" as contributing towards personal empowerment and the students' freedom to learn. When they know how to find and apply information, they can teach themselves what they need to learn, and essentially they would have learned how to learn. Resource-based learning is seen as a tool to achieve both subject and information literacy objectives through exposure to and practice with diverse resources.

The Malaysian Smart School Conceptual Blueprint, which is descriptive in nature rather than prescriptive, gives guiding principles as to the pedagogy and materials that will help children achieve self-paced, self-directed, and self-accessed learning. However, methods and tools used to achieve the aims of the Smart School are part of the evolutionary refinement allowed for in the Conceptual Blueprint.

\section{Information Literacy in the Smart School}

The Smart School Conceptual Blueprint recognises that one of the greatest challenge for society in this century is keeping pace with the knowledge and technological expertise necessary for finding, applying, and evaluating information. We live in an information-rich world where the amount of information and knowledge in the world is presently doubling every two years (Thornburg, 1997), and was predicted to have doubled in the year 2000 (Breivik and Senn, 1994).

Most people think of information literacy as a set of skills requiring technical ability, in other words, some form of "doing". True information literacy, however, involves both thinking and doing.

The world view of literacy has since been broadened to accept that literacy was evolving; that there was a continuum of skills associated with literacy; and that literacy itself was taking on various forms, in fact transforming, from a functional literacy through a set of literacies, tied to advances in technological society.

Owen, 1996 (as quoted in Langford, 1998) acknowledged that information literacy is demonstrated through our capacity to confidently challenge ideas because of our ability to access and use information effectively, but he goes on to expand information literacy to include: 
- That, beyond improving study and research skills, it serves to empower; to find out and act on information;

- It as a means of personal empowerment for all, not just students;

- Besides independent and self-directed learners, interdependent learners; and to

- Enrichment and enlivenment ... of lifelong learning.

The Smart School concept is premised on the belief that students should be educated to be "self-paced, self-accessed, and self-directed learners", with the teacher as "a guide by the side, not the sage on the stage." However, the very people responsible for empowering students to become lifelong learners, may not fully understand the information process, let alone information literacy, well enough to be truly effective learners themselves. Classroom teachers need to develop a belief, along with ensuing behaviours, in the teaching of enabling skills to permit students to construct their own knowledge and learn through independent and interdependent manipulation of information.

For a start, most teachers are not clear about what is meant by the term "information literacy" and how it relates to classroom practice. There is a need for teacher librarians and classroom teachers to work together in the same understandings and perceptions, and toward the same outcomes in an understood framework that is free from jargon, transferable from subject to subject, and a part of the natural discourse of educators. This requires a move from conceptual knowledge to standardised knowledge. Information literacy must become a part of all teaching practice and an embedded practice in the Smart School.

\section{Resource-based Learning as a Tool}

Advocates of information literacy promote resource-based learning as the methodological tool to realise it. Resource-based learning is based on the belief that students learn best by interacting directly with learning resources rather than only listening to classroom lectures. The learning is more self-directed and therefore more meaningful, and students retain the knowledge better because they learned it in a more engaging process.

Breivik (1994) calls resource-based learning "a down-to-earth, practical way of accomplishing the goals we've had in education for so long." These include making learning more authentic, encouraging interdisciplinary studies, developing more meaningful assessments, as well as accommodating learning styles and making inclusion more effective. Students are active learners (with teachers as guides by the side), and they are charged with finding information and turning it into knowledge - making their own meanings while integrating information from a variety of sources and media.

Since the skills of information literacy cannot be taught in a content vacuum, resource-based learning must integrate the classroom and the school resource centre.

For resource-based learning to work, teachers have to foster a process of discovery through which students learn how to use information sources effectively while pursuing questions they find meaningful. The student has to have a question to ask, a problem to solve, or a project to complete first before he goes about identifying resources, whether print, online, or human. Although the teacher's responsibility is to cover content (in other words, "to complete the syllabus"), he can surround the content with resource-based learning activities that help to make the learning experience more interactive, collaborative, and much more vivid for the student. 
Resource-based learning enables teachers to involve students in complex tasks that go beyond the limits of the classroom, beyond textbooks, and is more conducive to collaborative learning. By going beyond traditional classroom resources into the local community, the internet community, and the mass media, students develop more awareness of the source and nature of the many kinds of information.

\section{Exciting New Times}

With resource-based learning, teachers must either work very closely with teacher librarians who are library media specialists, or become library media specialists themselves. Instead of merely using provided materials, teachers must adapt the curriculum, work with students to set up the conditions for learning, and coach students through it. The two scenarios below illustrate how collaboration between classroom teachers and teacher librarians can help students become more independent learners.

\section{Sample Lesson Scenario I}

Mr. Hassan, a secondary school English Language teacher, collaborates with Mr. Tan, one of the school's teacher librarians, on a resource-based approach to learning about violence in the media. Mr. Hassan asks his students to conduct research in preparation for a multimedia presentation. The information skills objectives include:

- Appreciation: Watch a television programme, recording the number of violent acts, and discuss ideas about the impact of violence

- Presearch: Compare the number of violent acts across genres, use online search tools to find information on violence in the media, create a list of sub-topics, and brainstorm keywords for them

- Search: Interview a person or contact a group concerned with media violence, search resources for supporting data, and define "violent act"

- Interpretation: Develop a violence rating scale, determine the credibility of data and sources gathered, and write a review of one programme with an emphasis on violence

- Communication: Create a cartoon or comic strip on the subject, design an antiviolence programme for the school, and determine an effective method for reporting findings

\section{Sample Lesson Scenario II (adapted from O'Sullivan and Scott, 1999)}

Mrs. Sarah collaborates with Miss Normah to design a social studies lesson on Internet information literacy focussing on student evaluation of websites.

On the first day of the lesson, students learn to translate and dissect Universal Resource Locators (URLs). By learning such domain suffixes as .com, .org, .gov, .$e d u$, and others, students gain a greater awareness of where information originates and how the origin relates to the reliability of the information.

To demonstrate the potential for misinformation, which is easily encountered when conducting research on the internet, Mrs. Sarah and Miss Normah give a presentation which includes examples of unreliable websites. The teachers help their students 
understand that even .gov sites and .edu should not always be considered completely objective.

The teachers also introduce a strategy that librarians often use when evaluating print resources. The strategy includes five criteria: accuracy, authority, objectivity, currency, and coverage (Tate and Alexander, 1998), namely:

- Accuracy (Is the information reliable? Are the links accurate? Sources cited? Information believable?)

- Authority (Who is the author of the site? What are his/her qualifications? Is the site sponsored by an organisation? Is the organisation reputable or legitimate?)

- Objectivity (Does the information reveal a bias? What is the point of view of the author? Is the information trying to sway you? Do the links also reflect a bias?)

- Currency (When was the site last updated? Is the information kept up to date? Is the publication date indicated? Are the links up to date?)

- Coverage (How is the information presented? Heavy use of graphics, text, statistics? Topic coverage cursory or in-depth?)

By comparing three different websites, all dealing with the same topic, the students learn to apply these criteria to internet information.

On the second and third days of the lesson, students begin researching world history or global studies topics, including globalisation, global warming, human rights, and terrorism. While researching their topics using one of the popular search engines, students use the five criteria to evaluate the first three websites that appear.

When the lesson is complete, the teachers ask for student reactions. Various opinions are expressed, but all the students agree that the internet is a very useful research tool, but should never be used all by itself.

Mrs. Sarah and Miss Normah see that their students have learned to make responsible judgements about website information.

\section{Some Challenges - The Usual Suspects}

Adopting a resource-based learning model requires commitment at all levels. The biggest challenge is people. Change management monitoring activities carried out by the Smart School Pilot Project Change Management Team (Ministry of Education, 2002) have shown clearly that managing attitudes and learning to collaborate are more difficult than the more expensive task of equipping schools with technology.

Teachers and students working together as co-learners in dialogue with each other, as explorers in uncharted seas of learning is an area that has yet to be fully exploited.

Another aspect of change that seems difficult to accept is the idea of being comfortable with the ambiguity and uncertainty inherent in the new school technology. Teachers have to work at learning not only new technologies introduced in the Smart School project, but also how to evaluate the information that the new technology makes available. Teachers are not comfortable to find themselves learning alongside their students in the classrooms. Many would still prefer to be "sages on the stage."

Although training is the key to getting resource-based learning off the ground, teachers also need planning time built into the schedule. With the increased role of 
technology and greater staff collaboration as well as teacher-student collaboration, planning becomes even more critical and important.

For students to become information-literate, they will need access to information resources when a question comes up - not on a fixed schedule. Fixed regular visits to the school resource centre should become a thing of the past, and school administrators must now plan for students and teachers to access the school resource centre when the need arises.

\section{Next Steps}

The challenges and rewards of the teaching profession have never been greater. The range and type of information that students need to know far exceeds that of previous decades, and the academic expectations for all students are increasing in virtually every part of the country.

Considerable attention is being devoted by the Ministry of Education to ensure that the mindset of teachers is changed so that they understand that Smart Schools offer the best environment for self-paced, self-accessed, and self-directed learning.

Teachers must help students become active learners by allowing them to use a wide range of materials to investigate subject material prescribed by the curriculum.

Classroom teachers and teacher librarians must become motivators and facilitators in the learning process and provide the initial subject impetus that drives students to seek information and become creative problem-solvers.

\section{Bibliography}

Breivik, Patricia Senn and Senn, J. A. .(1994). Information Literacy: Educating Children for the $21^{\text {st }}$ Century. New York: Scholastic.

Cohen, Philip. (1995). "Developing Information Literacy". Educational Leadership Volume 37, No. 2.

Cohen, Philip. (1995). "Putting Resource-Based Learning To Work". Educational Leadership Volume 37, No. 3.

Kuhlthau, Carol C. (1995). "The Process of Learning from Information." School Libraries Worldwide, Vol. 1, No. 1.

Langford, Linda. (1998). "Information Literacy: A Clarification". School Libraries Worldwide, Vol. 4, No. 1.

Ministry of Education, Malaysia. (1997). The Malaysian Smart School: A Conceptual Blueprint. Kuala Lumpur: Ministry of Education.

Ministry of Education, Malaysia (2002). Change Management Programmes of Pilot Smart Schools: Draft Report. Kuala Lumpur: Ministry of Education. (unpublished)

O'Sullivan, Michael and Scott, Thomas J. (1999). "Information Literacy and the World Wide Web: Learning To Evaluate Internet Resources". Educational Leadership Volume 3, No. 2. 
Tate, M.A. and Alexander, J. E. (1999). Web Wisdom: How To Evaluate and Create Information Quality on the Web. New Jersey: Lawrence Erlbaum Assoc. Inc.

Thornburg, D.D. (1997). 2020 Visions for the Future of Education. Available:

http://www.tcpd.org/handouts/thornburg/2020visions.html 


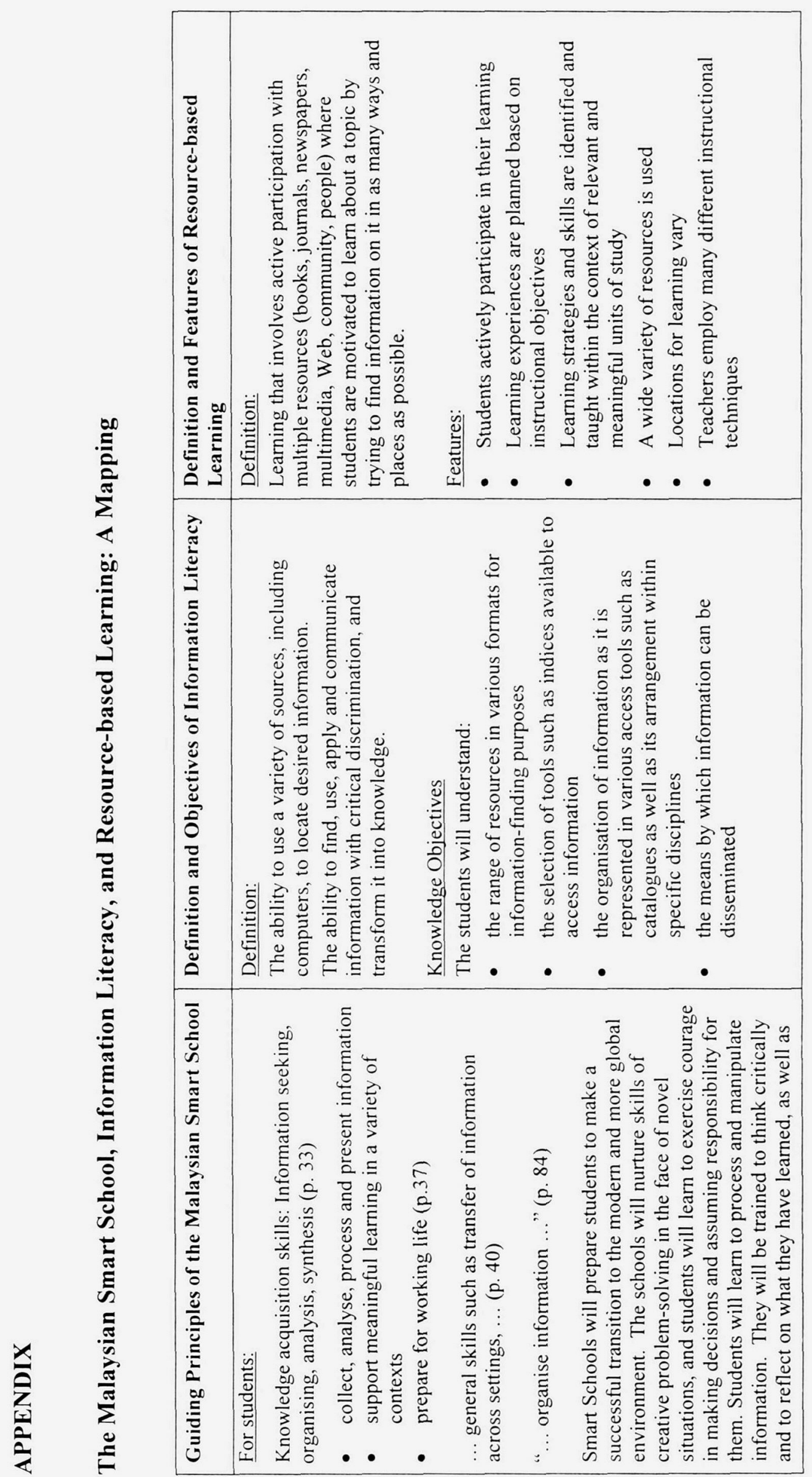




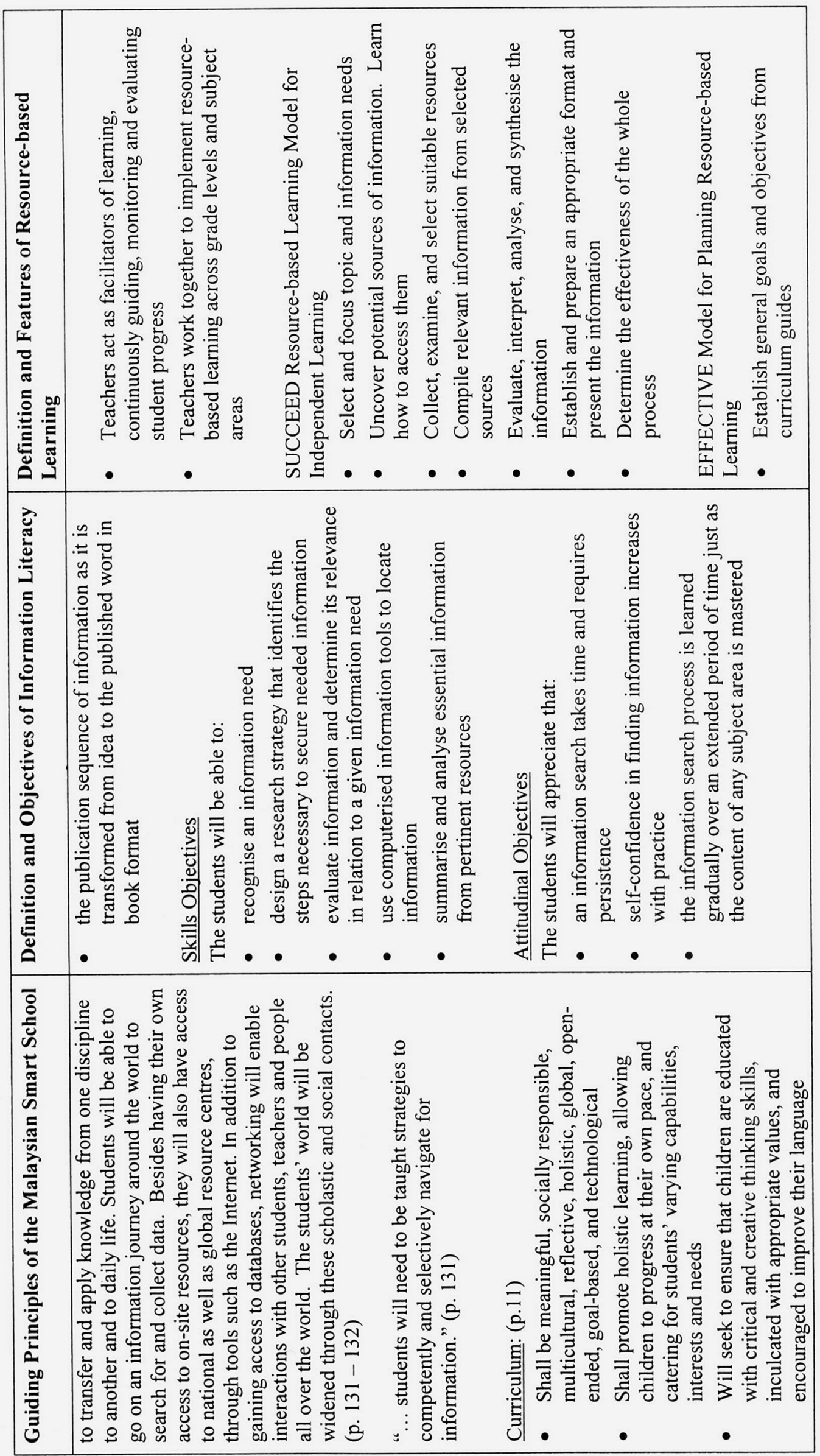




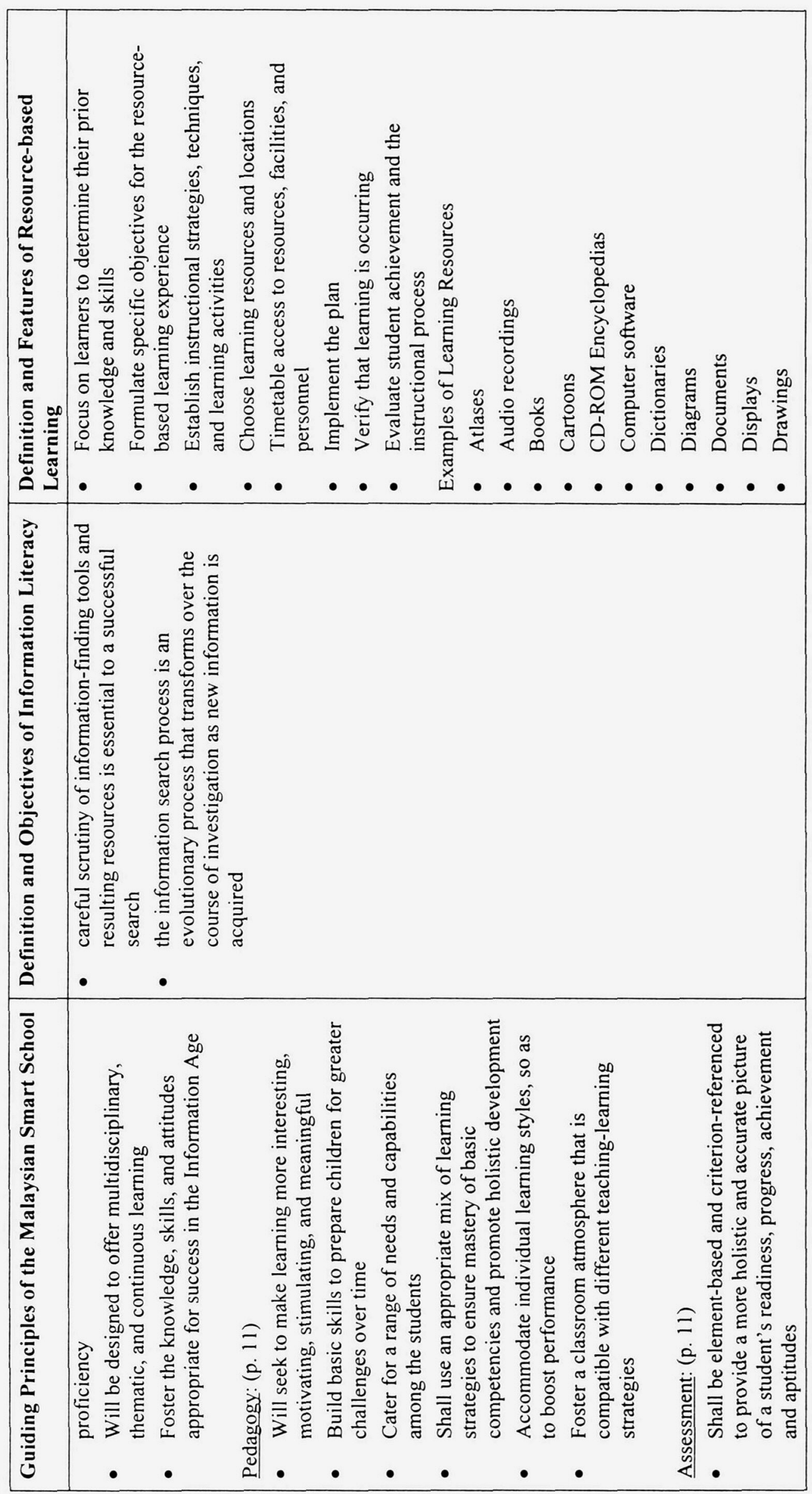




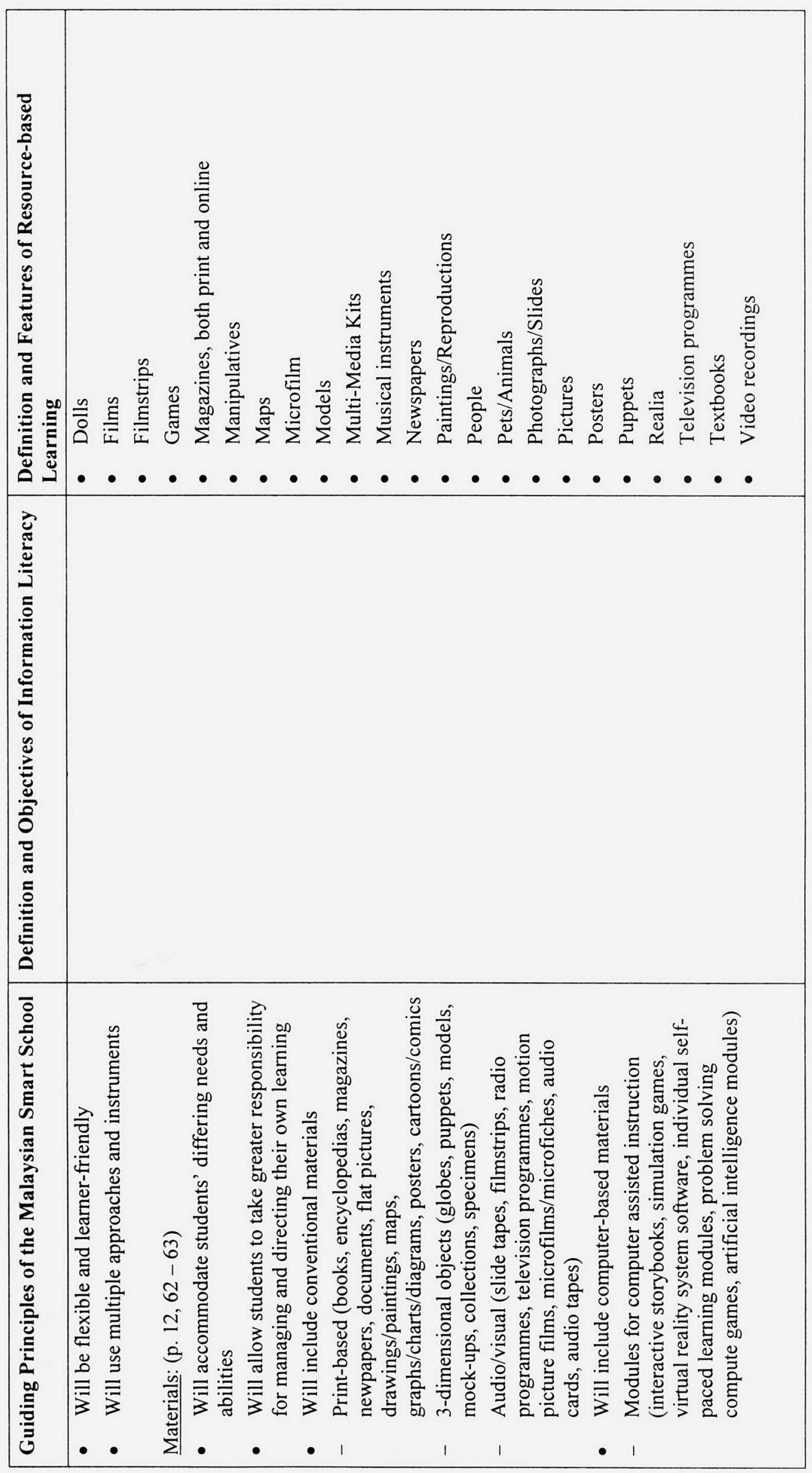




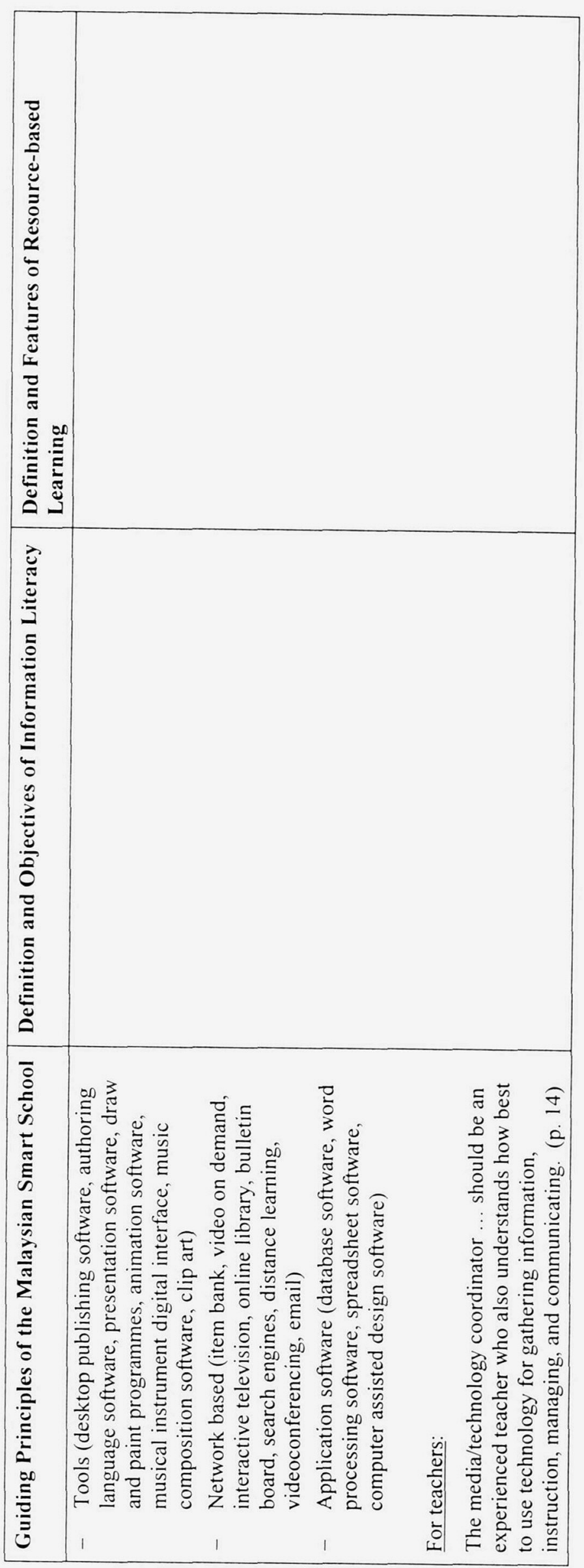

